\title{
DEVELOPMENT OF A PROTOCOL FOR A GIS RELATED TO THE RESTORATION OF CULTURAL HERITAGE BUILDINGS AND SITES THROUGH DOCUMENTATION STAGE
}

\author{
Stamnas Anastasios ${ }^{1}$, Georgoula Olga ${ }^{1}$, Patias Petros $^{1}$ \\ 1 School of Rural \& Surveying Engineering, Aristotle University of Thessaloniki, Greece - tstamnas@yahoo.gr, olge@auth.gr \\ patias@auth.gr
}

KEY WORDS: Cultural Heritage, Documentation, GIS, Educational toolkit.

\begin{abstract}
:
The Conservation and the Restoration of Cultural Heritage is a particularly specialized and interdisciplinary process. It requires scientific monitoring and planning and incorporation of skills and knowledge in the academic milieu. Relevant studies programs and courses are primarily designed to explore the possibility of cooperation between scientists (archaeologists, architects, surveyors, engineers etc.).

Participating in such an educational institution (Interdepartmental Program of Postgraduate Studies "Protection, Conservation and Restoration of Cultural Monuments", AUTh, Greece), the development of a protocol for a GIS related to the restoration of cultural heritage buildings and sites through documentation stage was born out of necessity.

A GIS application including the documentation (geometric, architectural, structural etc.) of the historical complex of Saint John, the Baptist (19th century, Kavala, Greece), while using modern 3D representational techniques (laser scanner, topography, photogrammetry, GPS), and the related thematic information (analysis, archive data) has been organized for that purpose and has been used as a case study.

The main objectives of the project are to give guidelines regarding the collection, the processing and the management of heritage data, to articulate the cross-disciplinary collaboration/synergy and to provide an educational toolkit. The methodology is proposed to be applied to other objects of study such as archaeological sites, individual structures, monuments and sites of different dating and use (e.g., industrial, religious, fortification etc.).
\end{abstract}

\section{INTRODUCTION}

The combination of digital technologies such as photogrammetry, 3D laser scanning and Geographic Information Systems (2D or 3D) and their contribution to digital preservation strategies have already been noted and defined variously in contemporary literature (Campanaro D.M. et al, 2016). Noteworthy research has been done on methodologies involving architecture and archaeology, conservation and restoration of monuments, graphic documentation and computer imaging (Canciani M. et al, 2013). Primary focus of these researches was placed on taking advantage of GIS environment and analytic tools for examining architectural structures, archaeological sites, monuments and objects in three-dimensions. The obtained products allow to the final user to manage digital documents providing graphic tools and integrated specific databases, supporting the entire conservation process at every stage, from a technical and management point of view, starting from the condition assessment until the restoration work (Pedelì C., 2013).

In addition, web-based platforms are used to spatially associate data with the 3D models of monuments and to provide an adequate view of the data, such as the so-called "health" record of a structure (geometry, nature and age of stone, weathering status, history and environmental conditions etc.) which provides a basis for scientific monitoring for the restoration work (Brunetaud X., et al, 2012). Furthermore, user-friendly software applications can be linked to virtual navigation platforms in real time and guarantee the optimal viewing with reasonable response time (Cignoni, P., Scopigno, R., 2008). In recent years, holistic and sophisticated approaches to the multidisciplinary documentation process have been proposed, including 3D Heritage Building Information Modeling (HBIM) systems, databases and further integration of non-destructive techniques and managing information regarding construction phases, pathology and current state of preservation of a monument in order to minimize the threats and risks of the past (Tsilimantou E., et al, 2020). Moreover, different HBIM protocols, methods and guides have been proposed in the literature having as main objective to link conservation principles, traditional heritage procedures and practical implementations with digital technologies (Jordan-Palomar I., et al, 2018).

Common feature of the majority of the above applications, methodologies and procedures is their implementation and testing in specific monuments or historical sites, used as case studies. Respectively, in the context of the present work the historical complex of Saint John, the Baptist (19th century, Kavala, Greece) was selected as pilot site (Figure 1) in order to apply certain representational techniques and recording and managing data tools, more specifically a multimedia and a GIS application that can be easily used as educational toolkits.

The selection of this historic site was made in the framework of the workshop of the Interdepartmental Program of Postgraduate Studies "Protection, Conservation and Restoration of Cultural Monuments", AUTh, Greece. Since 1998, the year of establishment of the Postgraduate Program, a great number of 
individual monuments and historical sites have been studied in the courses, workshops and diploma theses of students. Individual monuments of different uses (industrial, of worship and for religious activities, mixed, etc.) and of different dates (from antiquity to more recently) have been studied, as well as historical sites (the FIX industrial complex and the Pavlos Melas camp in Thessaloniki, the Halki Theological School in Istanbul, the historical center of Goumenissa, the rural settlement of Asfontilitis in Amorgos etc.) and many archeological sites (Vergina, Akrotiri of Santorini, Dion etc.), offering specialized knowledge, both theoretical and practical, for the study, maintenance, restoration and restoration of architectural monuments and sites.

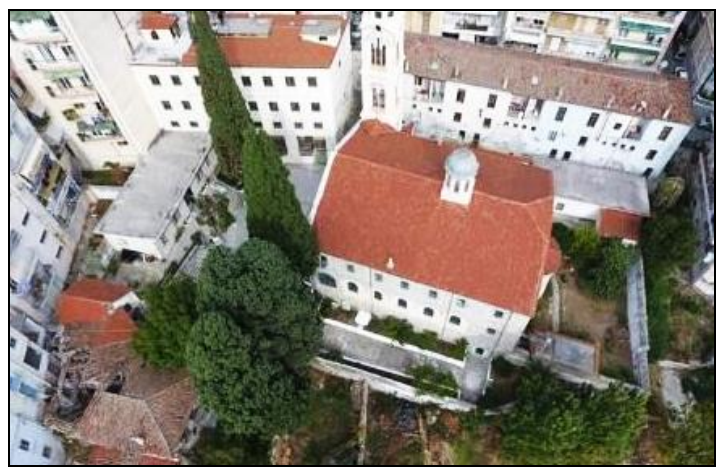

Figure 1. The historical complex of Saint John, the Baptist, as seen from above.

\section{STUDY AREA AND GEOMETRIC BACKGROUND}

The historical complex (19th century) of Saint John, the Baptist, is located in Kavala, eastern Macedonia, in Northern Greece. The complex consists of the Timios Prodromos church (1867), a modern event hall, two buildings north of the church (six houses in a row and a four-storey building next to them), a twostorey wooden mansion (1867), four houses in a row and a tobacco warehouse (1870-1877). The Saint John complex is located in the centre of the city, near the port, and at a short distance from the old city (Figure 2).

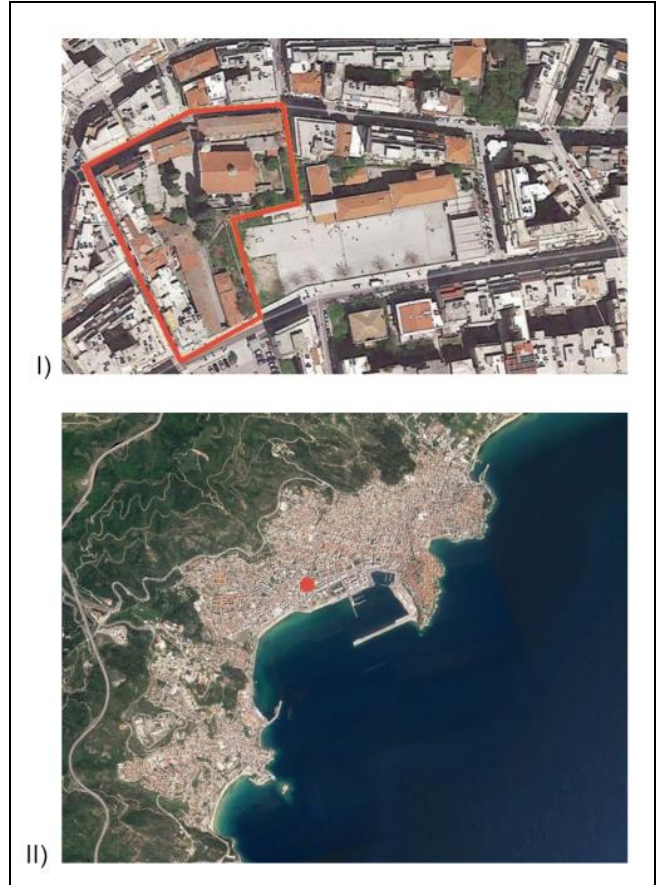

Figure 2. The location of (I) the historical complex of Saint John, the Baptist, (II) in Kavala, eastern Macedonia, in Northern Greece (Source: Google Earth)

This historical complex was the subject of the annual (20202021) workshop in which young scientists of different specialties participated, such as surveyors, architects, civil engineers, electrical and mechanical engineers, as well as archaeologists. It was considered ideal for interdepartmental cooperation and application of all modern methodologies and technologies of monument documentation and study. The necessary digital geometric backgrounds (2D \& 3D) were created to then form the basis for the architectural, static and electromechanical study of the entire complex.

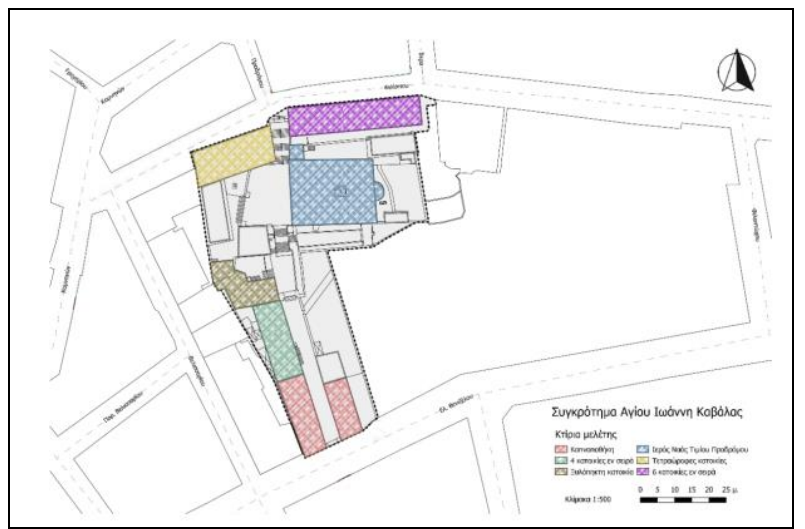

Figure 3. Topographic map of Saint John, the Baptist, historical complex.

Topographic mapping methods (Figure 3) were applied (points of details, building contours, levels, heights and elements of the façades) and architectural methods of direct measurements of objects or spaces with simple instruments, such as laser or tape measures. In addition, both inside and outside the buildings, a 3D laser scanning campaign was performed using the Faro Focus 3D phase comparison scanner and the Leica BLK360 time of flight scanner (Figure 4). Moreover, single and multicamera photogrammetry methods were performed, as well as 
aerial photogrammetry methods (especially for the roofs) using an unmanned aerial vehicle. The geometric background (plans, cross sections, façades, unfolded elevation drawings, 3D models) of the entire complex was essential for the analysis of the typological and morphological characteristics of each building, the drawings of construction materials, the drawings of the existing electromechanical installations (water supply, sewerage, high current electrical installations, heating, air conditioning).

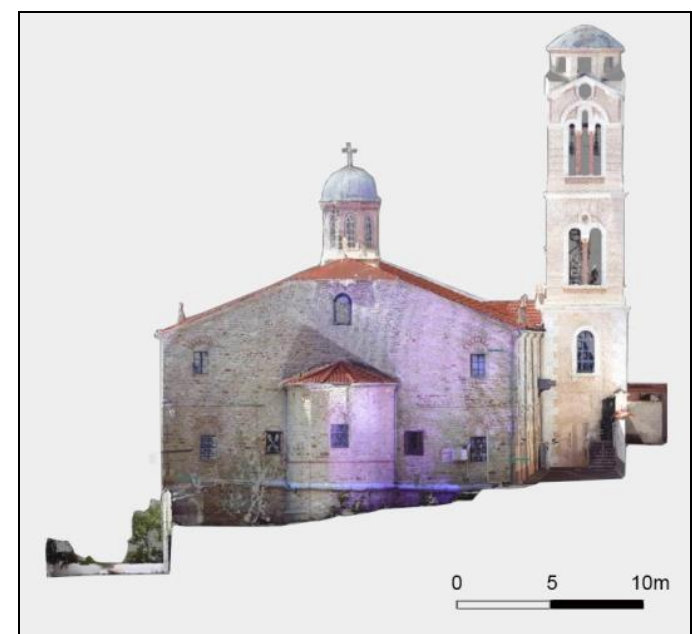

Figure 4. A point cloud of the east façade of the Timios Prodromos church using the Faro Focus 3D.

\section{METHODOLOGY}

As it is well known, scientists of different specialties participate in the restoration of monuments. Initially they cooperate in the completion of the study and then in its implementation on the respective monument or site. Depending on their specialty, scientists follow a set of theoretical and practical rules and tools at their disposal. For example, in terms of photogrammetry, standard rules and practices have been proposed years ago in the literature, such as the well-known "3x3 Rules for Simple Photogrammetric Documentation of Architecture" (Waldhäusl, P., Ogleby, C., 1994), that constitute the basis and the necessary methodology (upgraded for the digital era) for the image capture techniques in these studies. For example, in the Postgraduate Program, these rules are taught in all specialties in order to be able to attend and participate as much as possible in the process of photography. This is because one of the main educational goals of the Program is to stimulate cooperation between the different specialties. In order to achieve this, each specialty, from the beginning of the restoration study, should realize its own role in relation to the other specialties. Respectively, a methodology is proposed here (Figure 5) for the completion of a restoration study that consists of the following three entities: (I) an educational toolkit (a multimedia application) with the basic rules and stages, (II) a collection, organization and management system and (III) finally the completion and the presentation of the respective restoration study.

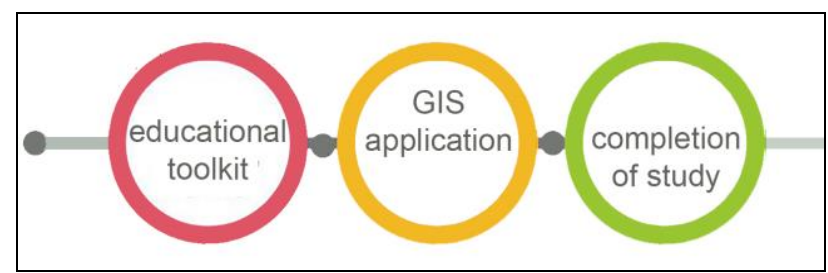

Figure 5. Overall workflow of the presented methodology.

\section{MULTIMEDIA APPLICATION}

In order to create a multimedia application that contains information and basic instructions and rules for a restoration study through documentation stage and that can be easily used as an educational toolkit, the specific work stages of each specialty involved in such a study were initially identified (Figure 6). The identification of these stages was essential for the organizational structure and the navigational system of a multimedia application (Figure 8).

The fact that many times the objects of study (monuments, archaeological sites, individual structures etc.) are located at long distances makes it necessary to define these work stages in order to limit errors, omissions, delays and unnecessary transportation (which can be interpreted as costs). Each stage concerns a different specialty but all together are carried out at the same time, while cooperation and synergy between all groups of researchers is necessary, as has already been said. In addition, all teams should be aware of what the others are doing. Each work stage includes individual steps and each step includes individual subsections of tasks. These subsections of tasks include both the collection of the necessary data in the field and the processing in the office that leads to the necessary products (drawings, diagrams etc.). More specifically in this application the following steps were identified as:

The "Initial study area analysis" phase consists of two steps: (I) the "Identification" and (II) the "Urban systems analysis".

- The "Archaeological research" phase comprises also two steps: (I) the "Background Study" and (II) the "Analysis and evaluation".

- The "Geometric documentation" phase consists of "Field Survey" and "Processing".

- The "Architectural analysis and documentation" phase involves three steps: (I) the "Architectural analysis", (II) the "Typological and morphological features" and (III) the "Current situation assessment". The "Documentation and Analysis of Structural System" phase includes three steps: (I) the "Description of Structural System", (II) the "Definition of Mechanical Properties of Building Materials" and (III) the "Description of Building Pathology".

Finally, the "Electrical and mechanical building installations / systems" phase consists of the "Infrastructure's documentation". 


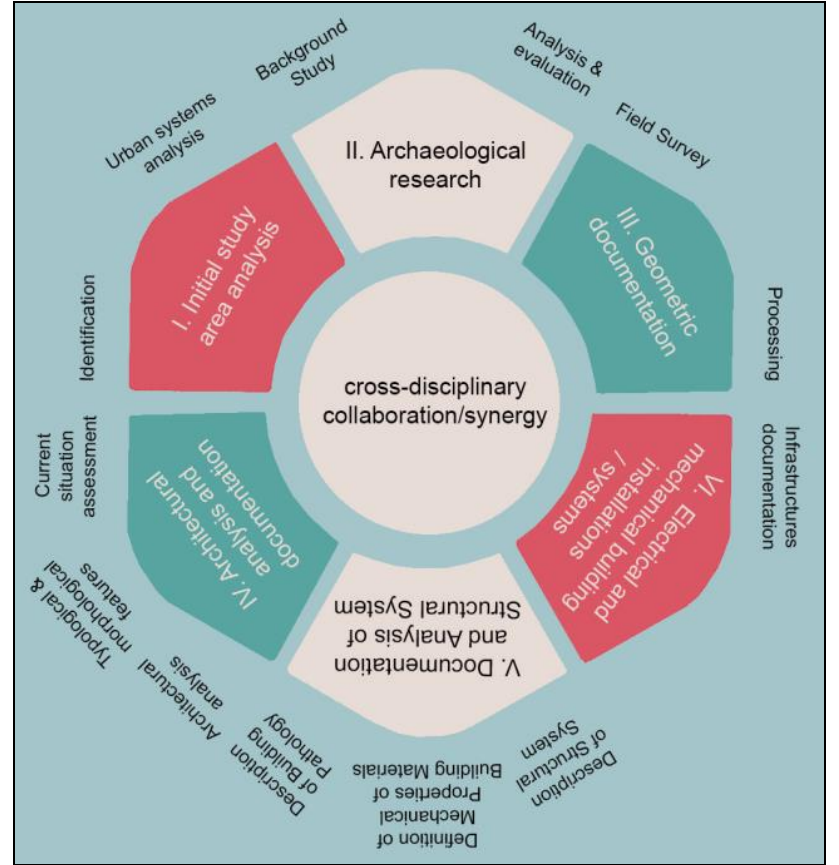

Figure 6. Work stages of restoration study through documentation stage.

For each step, the subsections of which it consists are then identified. Indicatively, we can mention that the section "Architectural analysis" consists of the following four subsections: (I) the "Geometric documentation", (II) the "Current situation plans", (III) the "Construction phases" and (IV) the "Building pathology". For each of these subsections, the elements from which they are organized were identified and recorded, such as: the deliverables, the file format, the software, the methodology, the equipment, the scale, the collaboration, the time required and possible comments (Figure 7).

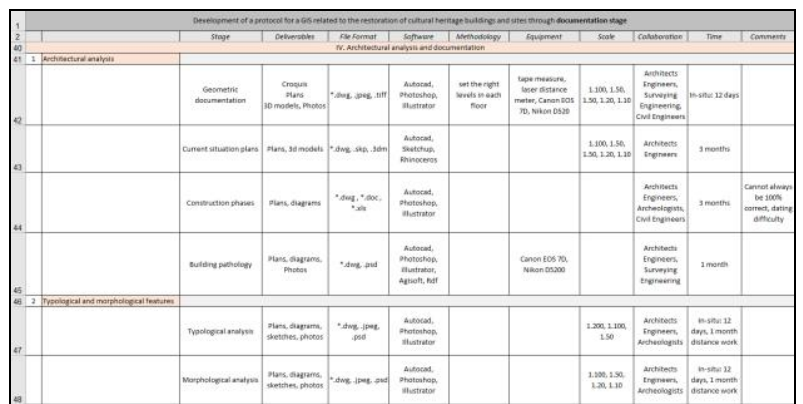

Figure 7. Subsections and records of work stages of restoration study through documentation stage.

Having organized all the above information, the creation (including planning, design, testing and delivery) of a multimedia application then followed (Figure 8). In this application are presented the specific stages of the restoration study, the software, the deliverables (plans, drawings), the specifications (scales, format) etc. This application incorporated indicative images, videos, drawings from the restoration study of the historical complex (19th century) of Saint John, the Baptist, located in Kavala, eastern Macedonia, in Northern Greece. Indicatively, the following figures show examples of products of certain work stages (Figure 9 of the Initial study area analysis, Figures 10 and 11 of the Geometric documentation and Figure 12 of the Architectural analysis and documentation).

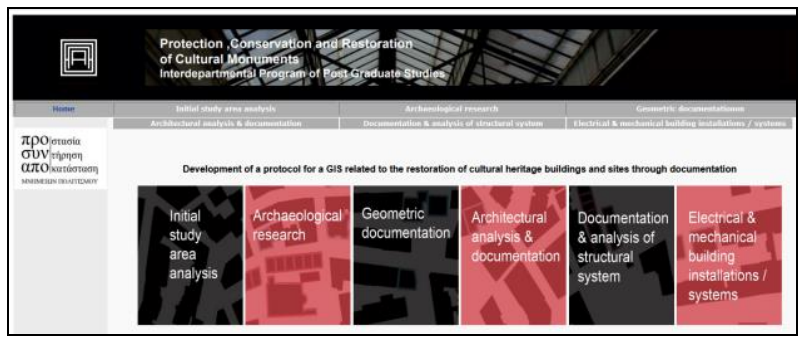

Figure 8. Layout of the multimedia application (presentation of work stages).

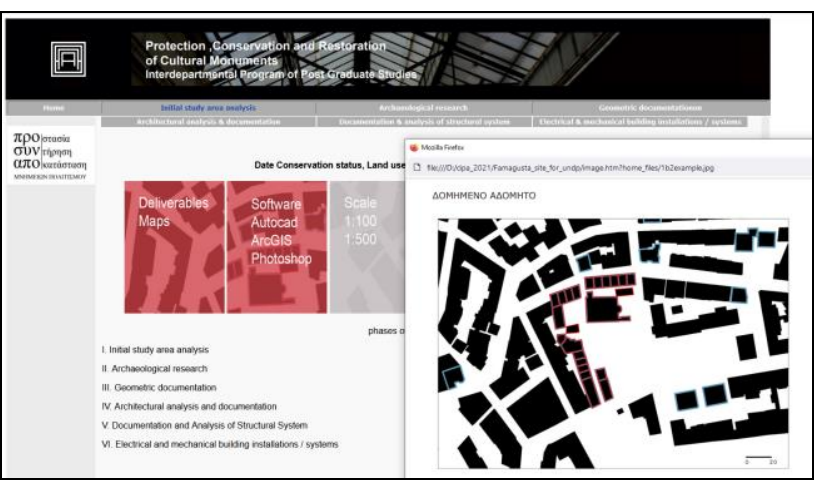

Figure 9. Layout of the multimedia application (presentation of

Initial study area analysis / Urban systems analysis / Date

Conservation status, Land use, Structured / unstructured,

Movements Heights / Example: Structured / unstructured areas).

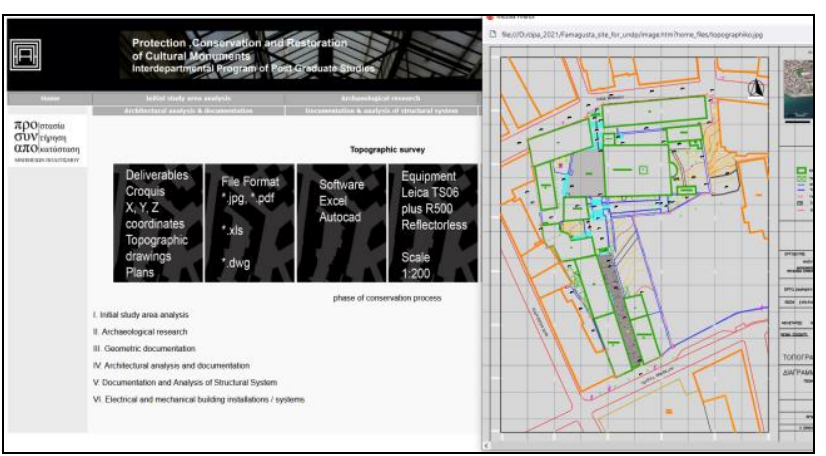

Figure 10. Layout of the multimedia application (presentation of Geometric documentation / Topographic survey / Example: Topographic map).

In summary, an attempt was made to characterize this multimedia application, which is a necessary part of the educational process, by the following parameters:

-It is as complete as possible and contains data for all work stages, whether they are performed in the field work phase or in the processing (office) phase.

-The interface is attractive and easy to structure, use and visualize.

-It is attuned to the modern trends-requirements of teaching and education.

-The structure should be, as far as possible, "open" for further additions and changes.

Finally, in the context of teaching it is necessary to understand and especially in a comprehensible way that all participants must fully understand the work stages of the restoration study and therefore a well-organized multimedia application is a 
necessary part of the educational process (even more so with the modern trends in education).

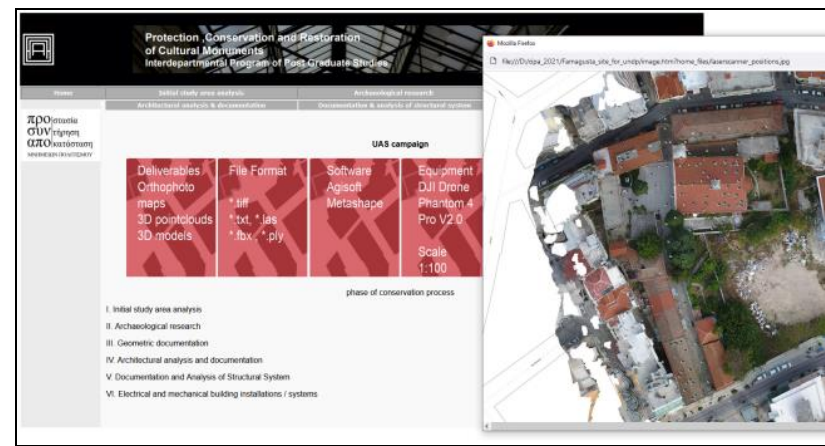

Figure 11. Layout of the multimedia application (presentation of Geometric documentation / UAS campaign / Example: Orthophoto map).

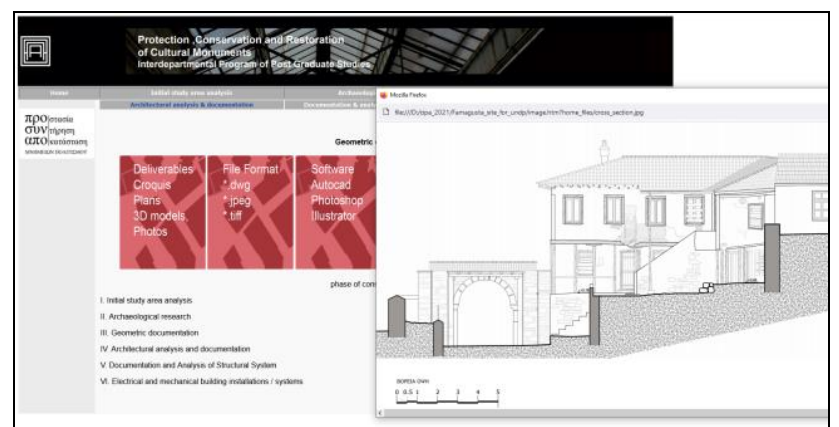

Figure 12. Layout of the multimedia application (presentation of Architectural analysis and documentation / Architectural analysis / Geometric documentation / Example: Cross section drawing).

\section{GIS APPLICATION}

As is well known, a GIS application is a collection, organization and management system. A restoration study, as shown by what has been mentioned and emphasized in the presentation of the multimedia application, concerns a large volume of data of different type and format. These data must be studied, analyzed and correlated with each other in order to complete the restoration study. Ideally, all of the above can be done using a GIS application. In addition, the different specialties that will deal with the final reuse proposal (architects, civil engineers etc.) will have at their disposal all the information, organized in the best possible way. In addition, the organization of such a system can contribute to the educational process for all specialties.

This GIS application was organized based on both the available documentation data of the historical complex of Saint John, the Baptist, and the needs and level of familiarity of users (archaeologists, architects, surveyors, engineers etc.) in these technologies. Taking into consideration the above two parameters, a part of the complex was selected to create initially a pilot GIS application.

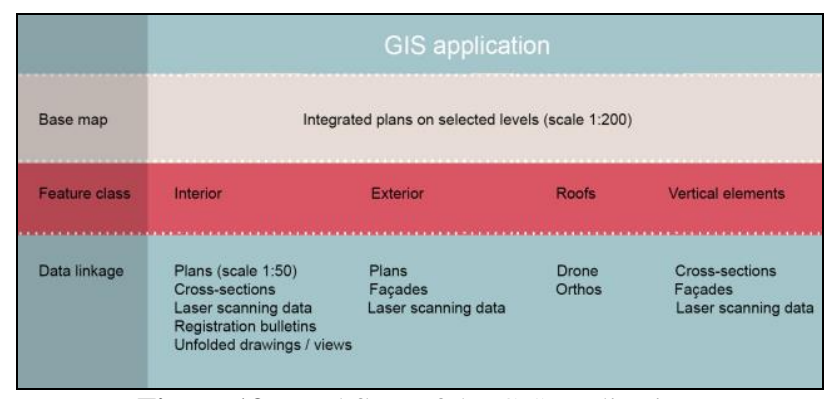

Figure 13. Workflow of the GIS application.

The geometric information (base maps) of the complex was organized in four basic levels (ground floor and three other floors) (Figure 13). Afterwards, the elements (interior, exterior, roofs and vertical elements) for which it would then be possible to integrate the corresponding thematic information (feature classes) were identified on each level. The structure and contents of a database were organized for this purpose. Depending on the feature class, different fields (surface, materials, type, state of conservation, floor, ceiling, use, ornament, morphological features, typological features, networks, infrastructures) in the database were created and hyperlinks (photos, videos) were also added (Figure 14).

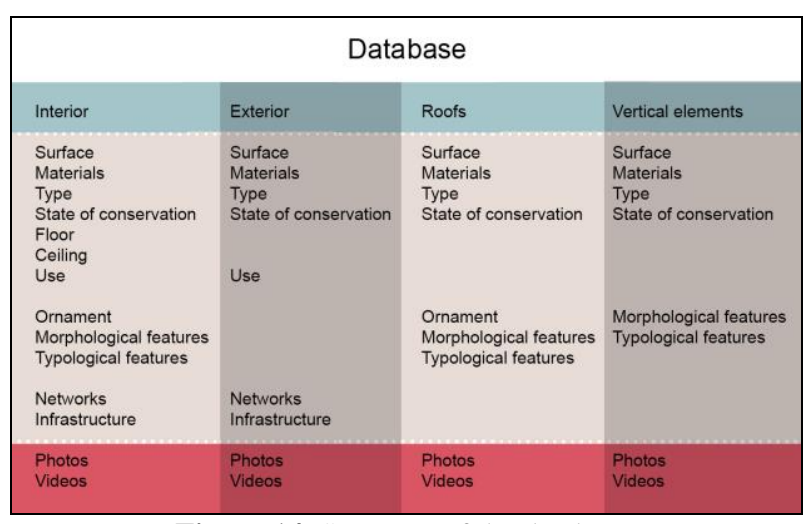

Figure 14. Structure of the database.

With this application additional information and data were as well connected such as: laser scanner data, file drawings, pathology drawings, registration bulletins etc. (Figures 15,16, $17,18,19)$

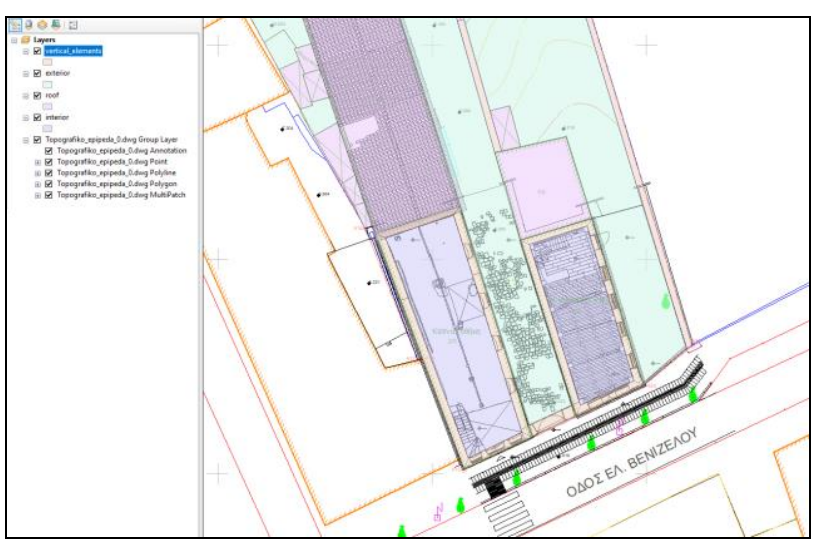

Figure 15. The GIS application (creation of different feature classes for interiors, exteriors, roofs and vertical elements). 


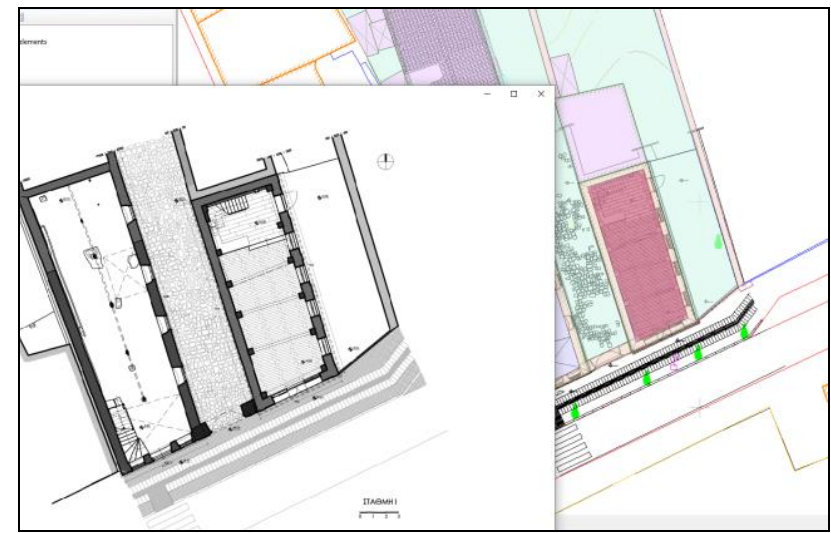

Figure 16. The GIS application (linkage of features classes with plans).

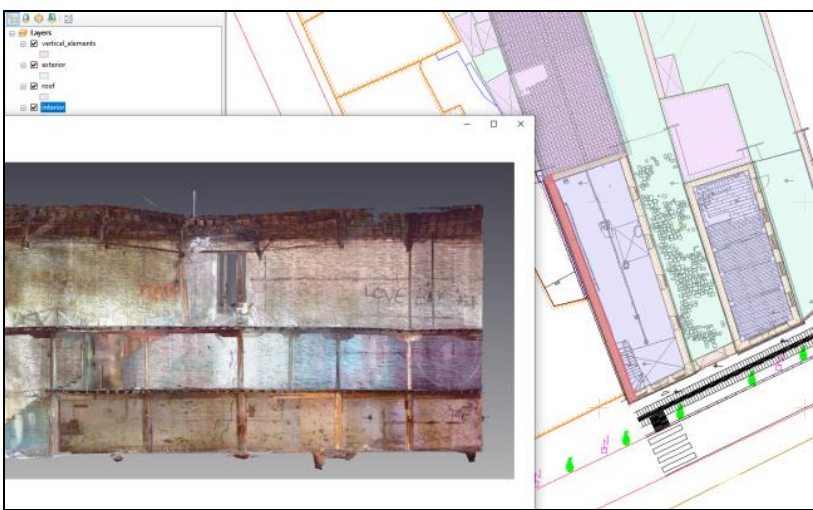

Figure 17. The GIS application (linkage of features classes with laser scanner data).

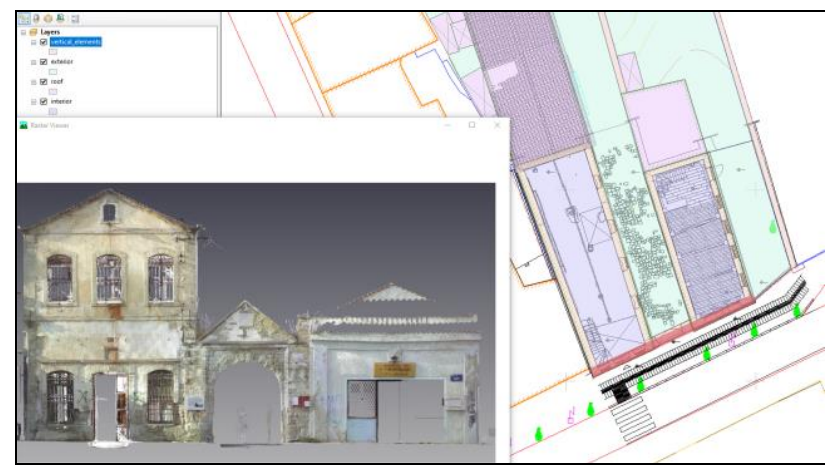

Figure 18. The GIS application (linkage of features classes with laser scanner data).

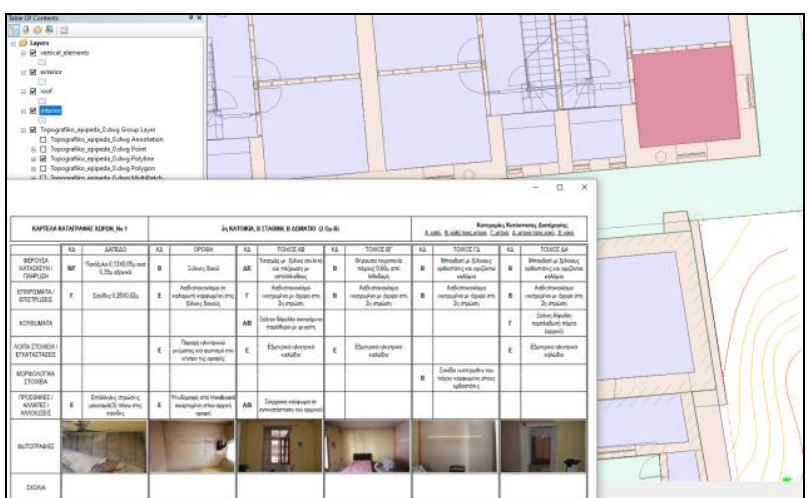

Figure 19. The GIS application (linkage of features classes with registration bulletins).
In addition, the GIS application can allow access and processing to all members of the study team through a webgis server, so that by using "strict" rules (restriction of free input and filtering of information) to interact with it (easier and safer use). In this way, users depending on their specialty (with different background and degree of familiarity) edit and view different data.

Finally, by completing the training process, users are motivated to be trained in such applications, as they are invited to contribute to the application with their own products, which will help them in the future to organize in more detail a restoration study and promote their work.

\section{COMPLESION OF STUDY}

Having already given instructions both in the field and in the office and trained with both previous entities (multimedia and GIS application) each specialty that participates in the restoration study, each study team is ready to proceed to the next stages of the study. The geometric information is now well organized and structured, there is easy access from everyone and the linkage with other data has been made (thematic information, testimonies, videos, photos etc.). All of the above are the documentation stage and the basis of a restoration study. Then, those involved in the restoration study can proceed with the architectural restoration and reuse study, the structural design study and the new networks and infrastructures study, in other words the completion of the restoration study (Figure 20).

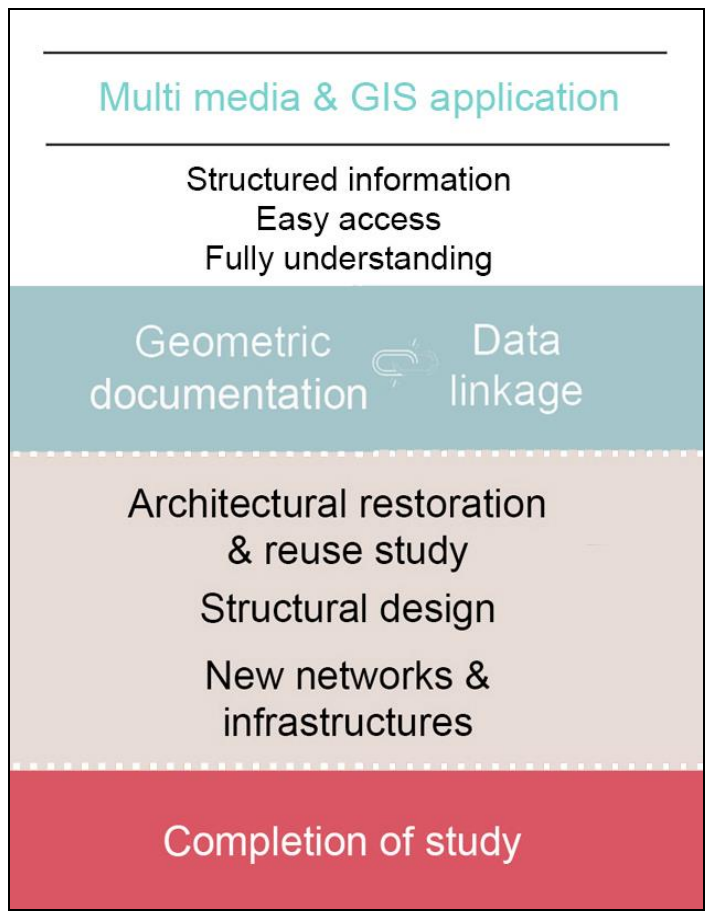

Figure 20. Workflow of the completion of a restoration study.

\section{CONCLUSIONS}

The possibilities offered by new technologies today are not limited to storage and recording (which are very important) but can be used as powerful tools for developing the creative abilities of those involved in the protection of cultural heritage. The methodology and the guidelines regarding the management of heritage data proposed here in order to articulate the crossdisciplinary collaboration/synergy and to provide educational 
toolkits can be applied to a variety of monuments and sites of different dating and use (e.g., industrial, religious, fortification etc.), archaeological sites, individual structures etc.

\section{ACKNOWLEDGEMENTS}

The authors want to thank all the participating professors and students in the Interdepartmental Program of Postgraduate Studies "Protection, Conservation and Restoration of Cultural Monuments", AUTh, Greece (2020-2021), who contributed with their work to the completion of the documentation stage (geometric, architectural, structural etc.) of the historical complex of Saint John, the Baptist.

\section{REFERENCES}

Ardissone, P., Bornaz, L., Degattis, G., Domaine, R.,2013. A 3d information system for the documentation of archaeological excavations, ISPRS - International Archives of the Photogrammetry Remote Sensing and Spatial Information Sciences, Strasbourg.

Baracchini, C., Lanari, P., Scopigno, R., Tecchia, F., Vecchi, A., 2003. SICAR: geographic information system for the documentation of restoration analyses and intervention, Proceedings Volume 5146, Optical Metrology for Arts and Multimedia, Optical Metrology, Munich, Germany, 149-160.

Barazzetti, L., Binda, L., Scaioni, M., Taranto, P., 2011. Photogrammetric survey of complex geometries with low-cost software: application to the 'G1' temple in Myson, Vietnam, J. Cultural Heritage 12 (3), 253-262.

Bianco, I., Del Giudice, M., \& Zerbinatti, M., 2013. A database for the architectural heritage recovery between Italy and Switzerland, ISPRS - International Archives of the Photogrammetry Remote Sensing and Spatial Information Sciences, XL-5/W2, 103-108.

Brunetaud, X., De Luca, L., Janvier-Badosa, S., Beck, K., AlMukhtar, M., 2012. Application of digital techniques in monument preservation, European Journal of Environmental and Civil Engineering, 16:5, 543-556.

Bushmakina, Y.V., Balyberdina, P. A., Dmitrieva, M.K., Gogoleva, M.V., 2017. The use of GIS for studying cultural heritage and historical urban landscape: the case of Perm and Usolie (Russia), Ge-conservación, V.11, 264-271.

Campanaro, D.M., Landeschi, G., Dell'Unto, N., Touati, A.M.L., 2016. 3D GIS for cultural heritage restoration: A 'white box' workflow, Journal of Cultural Heritage, V.18, 321-332.

Canciani, M., Ceniccola, V., Messi, M. Saccone, M., Zampilli, M., 2013. A 3d gis method applied to cataloging and restoring: the case of Aurelian Walls at Rome, International Archives of the Photogrammetry, Remote Sensing and Spatial Information Sciences, Volume XL-5/W2, XXIV International CIPA Symposium, Strasbourg, France, 143-148.

Centofanti, M., Continenza, R., Brusaporci, S., Trizio, I., 2011. The architectural information system siarch3d-univaq for analysis and preservation of architectural heritage, International
Archives of the Photogrammetry, Remote Sensing and Spatial Information Sciences, Volume XXXVIII-5/W16, ISPRS Trento Workshop, Italy, 9-14.

Cignoni, P., Scopigno, R., 2008. Sampled 3D models for $\mathrm{CH}$ applications: an enabling medium or a technological exercise? ACM Journal on Computing and Cultural Heritage, 1, 1-23.

Delegou E.T., Mourgi, G., Tsilimantou, E., Ioannidis, Ch., Moropoulou, A., 2019. A Multidisciplinary Approach for Historic Buildings Diagnosis: The Case Study of the Kaisariani Monaster, Heritage, V.2, 1211-1232.

Gulotta, D., Toniolo, L., 2019. Conservation of the Built Heritage: Pilot Site. Approach to Design a Sustainable Process, Heritage, V.2, 797-812.

Jordan-Palomar, I., Tzortzopoulos, P., García-Valldecabres, J., Pellicer E., 2018. Protocol to Manage Heritage-Building Interventions Using Heritage Building Information Modelling (HBIM), Sustainability, V.10, 908, 1-19.

Lianos, N., Stamnas, A., 2016. A recording and documentation system of building stock: the case of Pentalofos settlement in Kozani (Greece), Proceedings of the 8th International Congress on Archaeology, Computer Graphics, Cultural Heritage and Innovation 'ARQUEOLÓGICA 2.0', Valencia, Spain, 89-94.

Opitz, R., Nowlin, J., 2012. Photogrammetric modeling + GIS. Better methods for working with mesh data, ArcUser 57, 46-49.

Pappa, K., Georgoula, O., Stamou, A., Stamnas, A., Kafkoula, K., 2009. Record, Analysis and Documentation Using G.I.S. Applications for the Institutional Protection of Enoria Settlement in Greece',XXII CIPA Symposium in Kyoto, Japan.

Patias, P., Stamnas, A., Georgiadis, Ch., Stylianidis, E., Kaimaris, D., 2011. Mapping of Buildings facades at the historical center of Nicosia and creating a Preservation Information System, XXIIIrd International CIPA Symposium, Prague, Czech Republic.

Pedelì, C., 2013. An interdisciplinary conservation module for condition survey on cultural heritages with a $3 \mathrm{D}$ information system, International Archives of the Photogrammetry, Remote Sensing and Spatial Information Sciences, Volume XL-5/W2, XXIV International CIPA Symposium, Strasbourg, France, 483-487.

Shingh, V., Gu, N., Wang, X., 2011. A theoretical framework of a BIM-based multi-disciplinary collaboration platform. Autom. Constr., 20, 134-144.

Tsilimantou, E., Delegou, E.T., Nikitakos, I.A., Ioannidis, Ch., Moropoulou, A., 2021. GIS and BIM as Integrated Digital Environments for Modeling and Monitoring of Historic Buildings, Appl. Sci., V.10, 1078.

Vlahakis, V., Karigiannis, J., Karigiannis, J., Tsotros, M., Ioannidis, N., 2001. Archeoguide: First results of an Augmented Reality, Mobile Computing System in Cultural Heritage Sites, Conference on Virtual Reality, Archeology, and Cultural Heritage, Glyfada, Greece. 
The International Archives of the Photogrammetry, Remote Sensing and Spatial Information Sciences, Volume XLVI-M-1-2021 28th CIPA Symposium “Great Learning \& Digital Emotion”, 28 August-1 September 2021, Beijing, China

Waldhäusl, P., Ogleby, C., 1994. 3x3 Rules for Simple Photogrammetric Documentation of Architecture, Symposium of the ISPRS Commission V "Close Range Techniques and Machine Vision", Melbourne, Australia, 426-429. 